\title{
Analysis of the Impact of the Personal Income Tax Reform for Wages and Salaries on Income Redistribution in China
}

\author{
Jing Xue ${ }^{1}$, Li Lin $^{2}$ \\ ${ }^{1}$ Finance and Accounting Research Center, Fujian Jiangxia University, Fuzhou, China \\ ${ }^{2}$ Accounting School, Fujian Jiangxia University, Fuzhou, China
}

Email address:

xjing1970@163.com (Jing Xue),110006760@qq.com (Li Lin)

\section{To cite this article:}

Jing Xue, Li Lin. Analysis of the Impact of the Personal Income Tax Reform for Wages and Salaries on Income Redistribution in China. Social Sciences. Vol. 7, No. 3, 2018, pp. 146-151. doi: 10.11648/j.ss.20180703.16

Received: June 13, 2018; Accepted: July 12, 2018; Published: July 19, 2018

\begin{abstract}
The government in China carried out the personal income tax reforms in 2006, 2008, 2011 respectively, which focused on increasing deductions and reducing the tax rate brackets for wages and salaries. Using the survey data of the Urban Household of Income and Asset of 2013 from China Household Income Project, this paper will examine the impact of income tax reform for wages and salaries on income redistribution. The conclusion is that the personal income tax reforms are not efficient at improving income redistribution in China, but instead exaggerate the gap between individuals' tax burden of their wage and other income sources.
\end{abstract}

Keywords: Personal Income Tax Reform, Income Redistribution, Gini Index

\section{Introduction}

The big gap between the rich and the poor would distort the economic structure and cause the social turmoil. Fiscal policies are usually applied to redistribute wealth by the government in many countries, one of which is the personal income tax. In the last decade the Government in China is committed to set up a new tax system, which is conducive to social equity. As the keystone, the Government in China carried out the personal income tax reforms in 2006, 2008, 2011 respectively. The latest reform in 2011 focused on increasing tax deduction from 2000 to 3500 and reducing tax rate brackets for wages and salaries from 9 to 7. However, the gap between the rich and the poor in China has been widening in recent years. It is reported in the China Family Panel Studies 2015 that income and property inequality is becoming more and more serious in China. The top $1 \%$ families occupies $1 / 3$ of the total property in China while the bottom $25 \%$ families only have $1 \%$ of the total property, and the Gini index for residents' income changes from 0.3 in the early of 1980s to over 0.469 in 2015 . Hence, more and more people suggest the government to further increase the tax standard deduction for wages and salaries. Discussions about whether and how to reform the Personal Income Tax system to improve income redistribution have attracted considerable attention in China. Most literatures related to the topic support that the personal income tax reform in 2011 can't improve income equality in China. Some literatures explore the reasons: firstly, increasing the tax deduction will reduce the average tax rate for the high-income group, which will offset the effect of raising the tax progressivity on income equality. [1-3] Secondly, increasing the tax deduction for wages and salaries doesn't levy more from the wealthy but cause the fiscal loss which does harm to the government's redistribution capacity. [4, 5] Thirdly, the design of tax rate for the current Personal Income Tax System has some problems, for instance, too much tax rate brackets, over-closed brackets, too high marginal tax rate, which cause the negative effect on income redistribution. [6]

The datasets used in the above literatures are different, which can be classified into two categories. (1) One is from the Urban Household Survey (UHS) presided by the National Bureau of Statistics in China, only summary data of the household, integrated data for the different income groups, integrated data for the regions are published, specific micro data for the samples isn't in public. The Post-tax income and the personal income tax are the basic index to analyze the impact of the Personal Income Tax for wages on income redistribution. Some researches regard the disposable income as the post-tax income, and take the difference between the total household income and the disposable income as the personal income tax, which cause a deviation from the real amount. Some researches use the summary data to simulate the influence of the Personal Income 
Tax reform on residents' income redistribution by the distribution function. [7] All of these inferred data would reduce conclusion authenticity and policy reference significance. (2) The other is the micro data from the small-scale survey organized by the research projects or from the official levying data organized by the local taxation bureau. The data is undisclosed. The conclusion from the data can't be examed again by the readers, which is adverse to the credibility of the conclusion. In recent decade, there occur some disclosed micro surveys of households in China presided by some institutions, such as the Chinese Household Income Project (CHIP), the China Family Panel Studies (CFPS), the China Health and Nutrition Survey (CHNS), the China Health and the Retirement Longitudinal Study (CHARLS), which provide new data sources for the research of income redistribution. In the paper the Urban Dataset (2013) of the CHIP will be used as original data source to identify the impact of the Personal Income Tax reform for wages and salaries in 2011 on income redistribution in China based on the Gini index, tax progressive, average tax rate, just as the relative literatures did. Then the impact of the current Personal Income Tax reform on income redistribution will further be discussed in the context of the itemized levying system and from the residents' subjective perceptions, which is different from the relative literatures.

Given such, the rest of this paper is discussed as follows: Section 2 briefly introduces the Itemed Levying System of the Personal Income Tax in China since 2011. Section 3 describes the dataset established according to the CHIP. Section 4 computes the index of Gini, MT, EP, tax progressivity, average tax rate to assess the impact of tax reform of wages and salaries on income redistribution. Section 5 describes the impact of current tax system of wages and salaries on income redistribution under the itemized levying system. Section 6 concludes and suggests.

\section{Description of Itemized Personal Income Tax Levying System in China}

Comprehensive levying system for the Personal Income Tax is adopted in many countries, that is, one's taxable income from different source is charged by the uniform tax rules. However, the residents' income from different source will be levied by the different tax rules in China, which is called the Itemized Levying System. Income has divided into 11 categories according to the Personal Income Tax Law in China, including wages and salaries, income for self-employment, income from individual contract, income from personal service, income from contribution fee, income from franchise rights, interest, dividends and bonuses, leasing or transferring property income, accidental income and so on. ${ }^{(1)}$ At present the personal income tax revenue in China is still mainly from the wages and salaries which occupied $62.3 \%$ in the total personal income tax in 2013. ${ }^{2}$ Therefore the personal income tax reform in China chose to focus on the wages and salaries in the

(1) www.chinahotelsreservation.com

(2) http://xiangfan.hb-n-tax.gov.cn/art/2014/3/25/art_18766_381219.html past decade. The standard deductions for wages and salaries changed for three times, from 800 Yuan per month to 1600 Yuan per month in 2006, and then to 2000 Yuan per month in 2008, and finally to 3500 Yuan per month in 2011. The income tax rate for wages and salaries also changed, the progressive brackets have reduced from 9 to 7 and the corresponding progressive rates rang from $3 \%$ to $45 \%$. The aim for reform is to reduce tax burden for low-income groups. Give an example, those whose wages are from 2000 to 2500 Yuan per month need to pay the personal income tax at $5 \%$ and those whose wages are from 2500 to 3500 Yuan per month need to pay at $10 \%$ before 2011 , while they pay nothing for their wages after 2011.

Meanwhile, 10 categories of the income source other than the wages and salaries listed in the Personal Income Tax Law maintain the collection rules since 1980. For example, one's income from a single payment for the personal service under 4000 Yuan needs to pay personal income tax at the rate of $20 \%$ after a deduction of 800 Yuan, and income from a single payment from 4000 Yuan to 25,000 Yuan needs to pay at $20 \%$ after deducting $20 \%$ of the payment. With residents' income from the personal service, contribution fee, interest, dividend, bonus increasing rapidly these yeas in China, whether different collection rules for different categories will affect the redistribution function of the personal income tax will be explored in the following sections.

\section{Data}

The data used in the paper is from the China Household Income Project (CHIP), a wealth research data based on the household survey, which is from the China Institute for Income Distribution in Beijing Normal University. Because the rural residents in China needn't pay the personal income tax for their income, the dataset of the Urban Household of Income and Asset of 2013, which includes the income and expenditure information for 7175 urban households and 19887 individuals from 15 province, 126 cities, 234 counties in China is used in this paper. According to the research purpose, the main variables used in the paper are employment status at this job, total wage income from this job in 2013, total amount of income from other jobs in 2013, total disposable income of the household in 2013, total amount of the financial assets, total amount of the household debts at the end of 2013, total amount of the expenditure in 2013.

The individual samples who are household heads in their family and whose status are employment at their job are kept first, and the samples with missing values of the above variables are cancelled. A new dataset for the paper including 3745 individual samples is set up. Then some new variables needed are calculated here, such as the annual income tax for wage under different tax system, the wage income after the personal income tax, the ratio of wage income after the income tax to the disposable income of the household, the average tax rate. ${ }^{3}$

\footnotetext{
(3) Average tax rate equals to the amount of annual income tax for wages divided by wage income for every sample.
} 


\section{Analysis of the Impact of the Personal Income Tax Reform on Income Redistribution in China from the Perspective of Tax System}

\subsection{MT Index and the Average Tax Rate for Income Groups Under Different Personal Income Tax Systems}

Gini coefficient is the index usually used to measure redistribution inequality. The lower Gini coefficient is, the more equal for the income distribution. Here, Gini post $_{\text {and }}$ Gini $_{\text {pre }}$ are calculated to present the redistribution of wage income before tax and after tax. MT index and EP index are used to show the impact of the personal income tax on income redistribution. Musgrave and Thin (1948) created a way to measure the income tax progression in the basis of Gini index, which can be expressed by the absolute index (MT) or the relative index (EP). [8]

$$
\begin{gathered}
\text { MT }=\text { Gini }_{\text {pre }}-\text { Gini }_{\text {post }} \\
\mathrm{EP}=\left(1-\text { Gini }_{\text {post }}\right) \div\left(1-\text { Gini }_{\text {pre }}\right)
\end{gathered}
$$

If $\mathrm{MT}>0$ or $\mathrm{EP}>1$, the income tax system for wages and salaries has the positive impact on income redistribution, the more the better, conversely, negative effect.

The average tax rate, which is explained in Section 3, reflects the real income tax burden for individuals. It is the key factor to measure the effect of income redistribution. [9] Here the average tax rates among the different income groups are contrasted to show the impact of tax on income redistribution under different personal income tax systems for wages and salaries.

In China the latest reform for the personal income tax is in 2011, after that the proposal of increasing standard tax deduction to 5000 Yuan is frequently drafted in researchers' papers and NPC deputies' motions when more and more people are dissatisfied with income redistribution. Does the current personal income tax system have the positive influence on income redistribution? How does the effect of income redistribution change when the standard deduction for the wage income continues to be increased to 5000 Yuan followed by the proposal? The paper first calculates Gini index for the per-tax income, Gini index for the post-tax income, MT index, EP index and the average tax rates for the different income groups according to the current personal income tax system, old tax system before 2011, the tax system when increasing the tax standard deduction to $¥ 5000$ by the same dataset of 3745 samples, and then compare the outcomes to check the impact of personal income tax reform on income redistribution (see table 1,2,3).

The main outcome is presented in table 2, table 3, Figure 1 and Figure 2. The value of MT and EP in Table 2 shows the income tax system for wages and salaries in China has the positive influence on income redistribution. However, when comparing MT and EP under the current personal income tax system with the old income tax system before 2011, the values of MT and EP decline, which means the personal income tax system reform in 2011 doesn't improve the effect of income redistribution. If the tax deduction increases to 5000 Yuan, MT and EP decrease further. Why does it happen? The average tax rate of different income groups in Table 3 gives some interpretations: firstly, it seems that more low-income people benefit from the reform when the $60 \%$ samples whose monthly wage income is less than the levying threshold of 3500 Yuan exempt from the personal income tax under the current personal income tax system. Yet, compared to the $20 \%$ samples exempt from the personal income tax under the tax system before 2011, we can find $0-20 \%$ income group gains no benefit from the personal income tax reform in 2011. In the mean time the progressive tax rate with 7 brackets makes more benefit to $70-80 \%, 80-90 \%, 90-95 \%, 95-100 \%$ income group. Their average tax rate reduces from $5.3 \%$ to $0.7 \%$, $7.29 \%$ to $1.75 \%, 9.27 \%$ to $3.66 \%, 12.86 \%$ to $8.69 \%$ respectively, which means the medium-high income class makes the greatest contributions to the income tax revenue, but the average tax rate for the high-income class decreases more than that for other groups under the current income tax system for wages and salaries. If the tax deduction increases to 5000 Yuan, the trend is much obvious. Therefore, the personal income tax reform weakens the effect of income redistribution.

Table 1. Sampling statistics for main variable (Unit: Yuan).

\begin{tabular}{lllll}
\hline variable & obs & mean & std. dev. & min \\
\hline pre-tax income (total wage income in 2013) & 3745 & 42229.76 & 29969.7 & 600 \\
tax payable by tax system before 2011 & 3745 & 2371.98 & 4521.95 & 0 \\
tax payable by tax system at present & 3745 & 873.2 & 3574.52 & 0 \\
tax payable when tax deduction is raised to ¥5000 & 3745 & 488.76 & 3013.00 & 0 \\
post-tax income by tax system before 2011 & 3745 & 39857.77 & 25706.42 & 60000 \\
post-tax income by tax system at present & 3745 & 41356.64 & 27153.17 & 600 \\
post-tax income when tax deduction is raised to $¥ 5000$ & 3745 & 41740.99 & 27883.97 & 600 \\
\hline
\end{tabular}

Notes: (i) Tax payable for wages is levied on monthly basis. (ii) Social insurances and qualified housing accumulation funds which need to be deducted from the total wage income are neglected here. (iii) The lump-sum bonus per year which should be paid income tax by its own tax rules is also neglected. (iv) Tax payable $=[\text { (monthly wage }- \text { tax deduction })^{*}$ tax rate-quick deduction factor $]^{*} 12$.

Table 2. Gini, MT, EP index under different personal tax system.

\begin{tabular}{lllll}
\hline & Gini for pre-tax income & Gini for post-tax income & MT index & EP index \\
\hline old personal tax system before 2011 & 0.343 & 0.322 & 0.021 \\
current personal tax system (from 2011) & 0.343 & 0.332 & 1.032 \\
Proposal of raising tax deduction to $¥ 5000$ & 0.343 & 0.336 & 0.012 & 0.007 \\
\hline
\end{tabular}


Table 3. Average tax rate for income groups under different personal income tax system.

\begin{tabular}{|c|c|c|c|c|c|c|c|c|}
\hline Income group & $0-20 \%$ & $20-40 \%$ & $40-60 \%$ & $60-70 \%$ & $70 \%-80 \%$ & $80-90 \%$ & $90-95 \%$ & $95-100 \%$ \\
\hline average tax rate before $2011(\%)$ & 0 & 0.53 & 2.52 & 3.89 & 5.30 & 7.29 & 9.27 & 12.86 \\
\hline average tax rate at present $(\%)$ & 0 & 0 & 0 & 0.17 & 0.70 & 1.75 & 3.66 & 8.69 \\
\hline average tax rate when raising tax deduction to $¥ 5000$ (\%) & 0 & 0 & 0 & 0 & 0 & 0.28 & 1.54 & 6.27 \\
\hline Average income (Yuan) & 13285.79 & 26550.67 & 36103.71 & 44183.4 & 52569.99 & 66156.08 & 85787.21 & 128744 \\
\hline
\end{tabular}

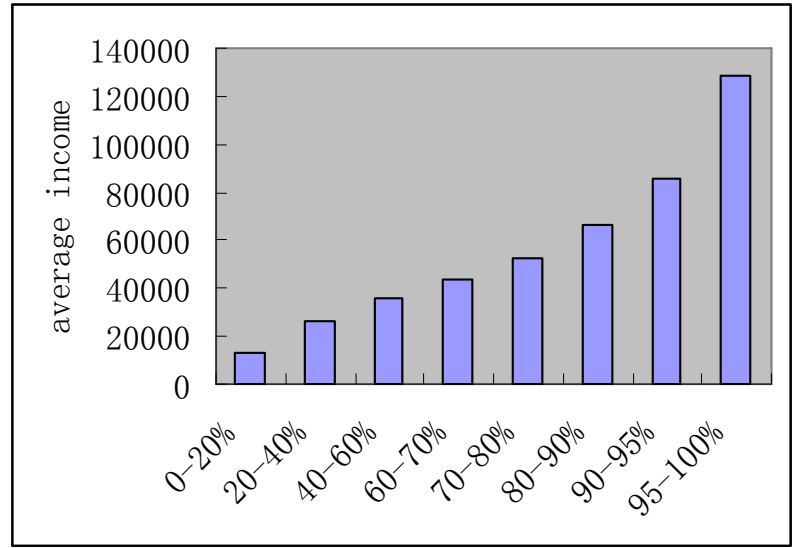

Figure 1. Average income for income groups (3745 samples).

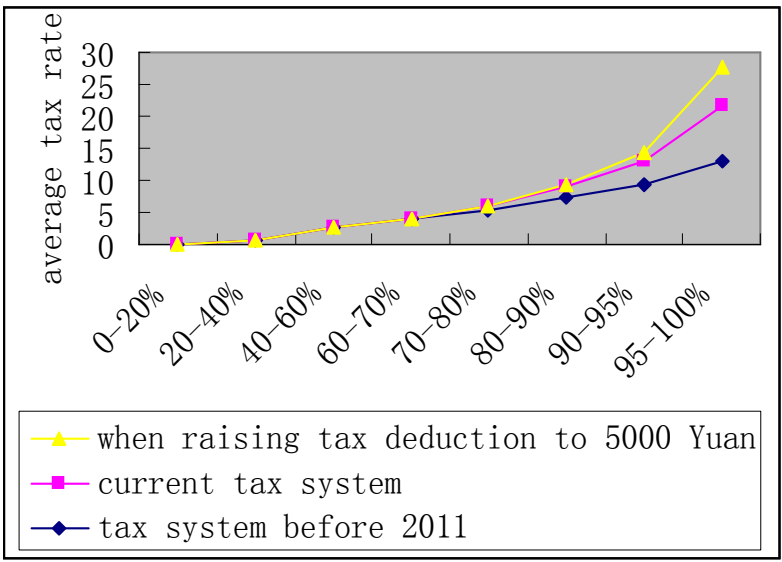

Figure 2. Average tax rate for income groups under different tax system (3745 samples).

\subsection{Further Discussing the Impact of the Personal Income Tax for Wages and Salaries on Income Redistribution from $K$ index and Average Tax Rate}

MT index and EP index reflect the effect of income redistribution just by simply comparing Gini post $_{\text {index with }}$

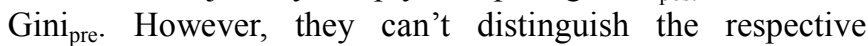
contribution of raising the tax deduction and changing the tax rate and the rate brackets on income redistribution. So MT index is decomposed into $\mathrm{K}$ index and the average tax rate in the light of the literature written by Kakwani. [10]

$$
\text { MT }=\mathrm{Gini}_{\text {pre }}-\mathrm{Gini}_{\text {post }}=\mathrm{r} /(1-\mathrm{r}) \times \mathrm{K}
$$

$\mathrm{r}$ stands for the average tax rate, $\mathrm{K}$ stands for the degree of the tax progressivity, which equals to the area between Lorenz Curve for the pre-tax income and the tax concentration curve, So $\mathrm{K}=\mathrm{C}-\mathrm{Gini}_{\text {pre }}$. [11] C stands for the tax concentration, which is the accumulative proportion of tax payable in the taxable income for income groups. If the accumulative proportion of the tax payable grows with increasing the taxable income, the tax concentration curve is under the Lorenz Curve for the pre-tax income $(\mathrm{K}>0)$, namely, the personal income tax is progressive. If the tax concentration curve is above Lorenz Curve for the pre-tax income, $\mathrm{K}$ is less than 0 , that is, tax is regressive. If the tax concentration curve is coincident with the Lorenz Curve for pre-tax income, $\mathrm{K}$ equals to 0 , and tax is proportional.

In the case of other conditions unchanged, MT index improves or reduces when the average tax rate and $\mathrm{K}$ increase or decrease. The more the tax deduction from the living expense, the more progressive $\mathrm{K}$ will be. It is shown in the existing literature that there is an inversely proportional relationship between the tax progressivity and the average tax rate. [12] $\mathrm{K}$ index is used to measure the tax progressivity, thus the relationship between the tax rate and $\mathrm{K}$ index is negative. [13] Table 4 shows that when the standard tax deduction raised from 2000 Yuan to 3500 Yuan, and further from 3500 Yuan to 5000 Yuan, the tax progressivity $\mathrm{K}$ is accelerated while the average tax rate is double decelerated, which is followed by the above law.

The negative relationship between the average tax rate and $\mathrm{K}$ index somewhat may do harm to income redistribution. Alm described in his literature about the income redistribution effect of the Tax Reform Act of 1986 that reform of the tax deduction made the personal income tax more progressive but at the same time decreased the average tax rate from $50 \%$ to $35 \%$ for the high-income group, which resulted in the declination of income redistribution function of the personal income tax. [14]

As for China, the income redistribution function of the personal income tax after 2011 declines owing to the over-low average tax rate other than the tax progressivity for the wage income. Besides for the unreasonable design of the tax rate for the wage income itself, the imperfect Tax Administration and Collection Law in China is partly to blame for the low average tax rate. In China only 28 million people pay for the personal income tax, which only occupy $2 \%$ of the whole population in China ${ }^{\circledR}$, while there were $4.68 \%$ in other developing country nearly 30 years ago. Although the tax administration for wages and salaries is more standardized than before, many benefits in kind and cash transactions are still the loopholes in the tax collection. There exists a lot of off-the-books income for the residents, most of which is from the rich. The off-the-books income for the top $20 \%$ income group accounts for about $80 \%$ of

(4)http://news.youth.cn/gn/201503/t20150309_6512912.htm 
the total residents' off-the-books income in China. [15] It was proved that the off-the-books income has the positive correlation with the income gap between the wealthy and the poor. [16]
Hence, the effectual fiscal way to improve income distribution is not further raising the standard tax deduction for the wage income but to optimize the tax rate and its brackets to conform to the principal of equal redistribution.

Table 4. Average tax rate and $K$ index under different income tax systems.

\begin{tabular}{lllll}
\hline & effect of redistribution & \multicolumn{2}{l}{ Gini for pre-tax } & \multicolumn{2}{l}{ tax concentration } & \multicolumn{2}{l}{$\begin{array}{l}\text { tax progressivity (K) } \\
\text { income (2) }\end{array}$} & $\begin{array}{l}\text { average tax } \\
\text { rate (C) (3) }\end{array}$ & 0.0561626 \\
\hline (MT) (1) & 0.0215 & 0.3432479 & 0.7059147 & 0.3626668 \\
tax system before 2011 & 0.0117 & 0.3432479 & 0.895316 & 0.5520681 \\
$\begin{array}{l}\text { current tax system } \\
\text { tax system when raising tax }\end{array}$ & 0.0071 & 0.3432479 & 0.951076 & 0.6078281 \\
deduction to ¥5000 & & & 0.011571 & 0.06703 \\
\hline
\end{tabular}

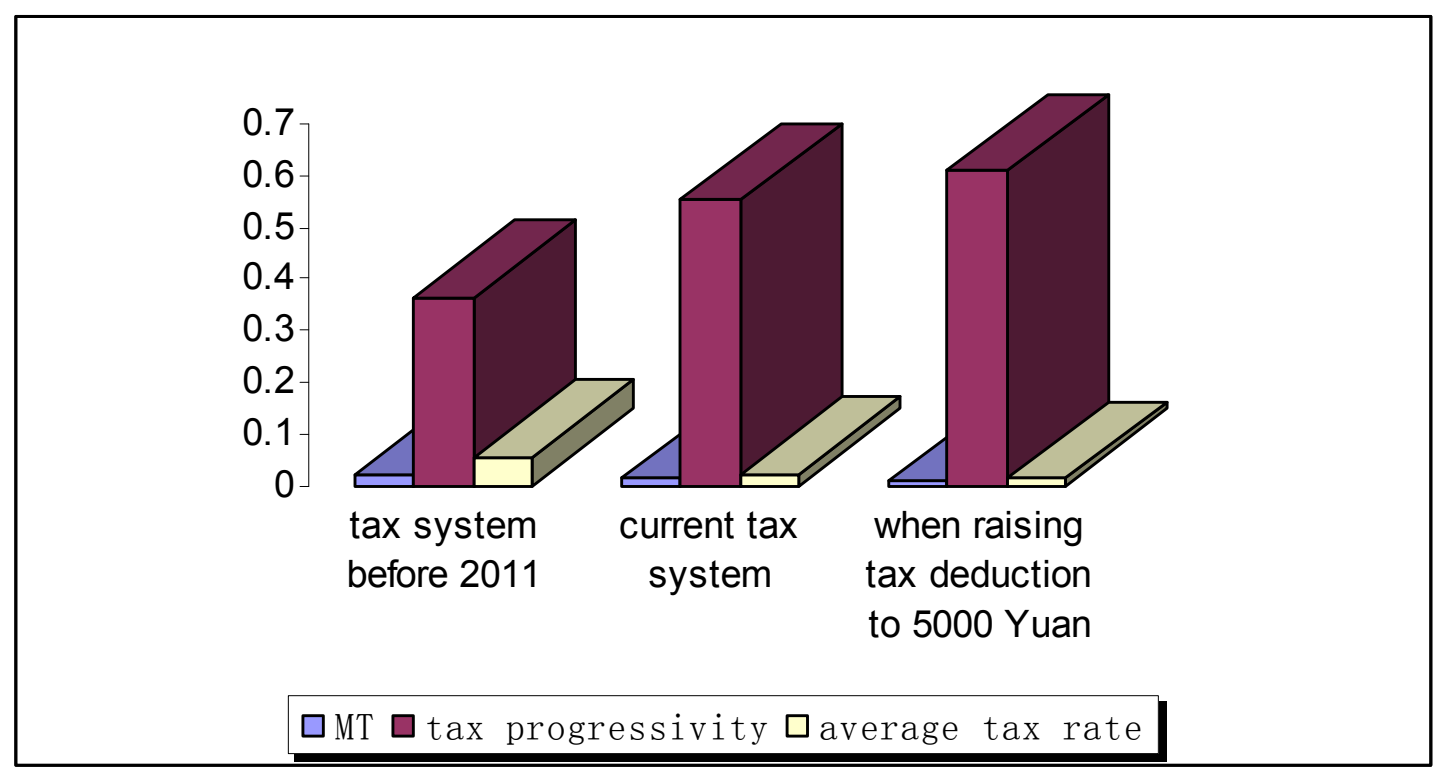

Figure 3. Comparison of $M T, K$, average tax rate under different tax systems.

\section{Tax Burden Inequity between Wages and Service Income under the Itemized Levying System of the Personal Income Tax in China}

As described in section 3, different types of income are assessed to tax by different tax rules under the itemized levying system in China. All of the personal income tax reform in China is aimed at the wage and salary income. Though the wage and salary is still the main source of income for many people in China, other income sources are sharing more and more in the residents' total income with the development of economy. For the dataset of this paper, the proportion of the wage income after income tax in the disposable income is about $57 \%$ in average annually. The income from author's remuneration or from the personal service, which are also the labor income, are levied by greater amount of tax than that for wages and salaries because the tax rules for other income source other than wages and salaries have never changed since the Personal Income Tax Law was issued in 1980. When the residents' income source has changed from the single wages to the diversified income source, the personal income tax reform for wages and salaries will further widen the tax burden gap between the wages and other labor incomes under the itemized levying system, which is negative to income redistribution. The empirical test is as follows.

Assume the annual income for 3475 samples in the dataset is from the personal service, and then calculate the income tax they need to pay according to the current tax law. The results are presented in Table 5 and Figure 4. When one gets the same payment from his service work as his wages from his jobs, the tax he pays is different. The tax burden for income from service is apparently heavier than that for wages. The lower the income group, the heavier the tax burden. If the personal income tax system reform in China continues to focus on the wages and salaries, it will exaggerate the inequality of income distribution. Hence, it is often mentioned by the researchers that income from the work and service including wages, author's remuneration and income from the personal service should be levied by the uniform tax law to show fair principle of the tax system. 
Table 5. Comparing average annual tax rate between wage and income for personal service.

\begin{tabular}{|c|c|c|c|c|c|c|c|c|}
\hline Income group & $0-20 \%$ & $20-40 \%$ & $40-60 \%$ & $60-70 \%$ & $70-80 \%$ & $80-90 \%$ & $90-95 \%$ & $95-100 \%$ \\
\hline Average tax rate for wages and salaries (\%) & 0 & 0 & 0 & 0.17 & 0.60 & 1.75 & 3.66 & 8.69 \\
\hline Average tax rate for service income (\%) & 7.41 & 12.77 & 14.68 & 15.65 & 16 & 16 & 16 & 16.09 \\
\hline Average income (Yuan) & 13285.79 & 26550.67 & 36103.71 & 44183.4 & 52569.99 & 66156.08 & 85787.21 & 128743.9 \\
\hline
\end{tabular}

Notes: (i) The tax payable for the personal service is assumed to be levied on monthly basis. (ii) tax payable $=[($ monthly single payment-deduction $) *$ tax rate-quick deduction factor] ${ }^{*} 12$ (iii) Progressive tax rate for the three brackets is $20 \%, 30 \%, 40 \%$ respectively, the corresponding quick deduction factor is 0 , 2000,7000

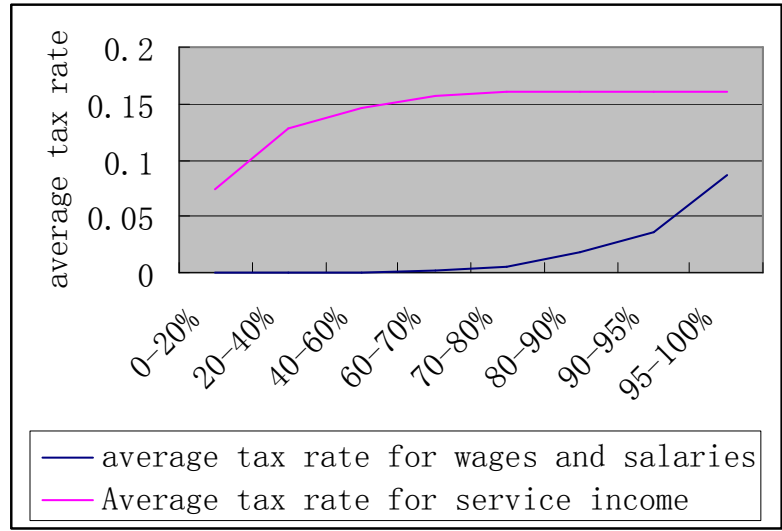

Figure 4. Average tax rate for wage income and service income.

\section{Conclusion}

Designing the scientific and fair tax deduction in the personal income tax system to improve income redistribution is a universal policy in many countries, so is it in China. In the past decade, the personal income tax reform in China focused on raising the tax deduction for wage income to improve the income tax progressivity for sake of reducing the income gap between the wealthy and the poor. However, it is invalid to only count on the progressive personal income tax to realize the ideal income redistribution. [17] The paper is not aimed to deny the personal income tax reform in China but offer proposals for the personal income tax reform from the perspective of improving income redistribution.

\section{Acknowledgements}

This work was supported by the Training Program of Fujian Excellent Talents in University in China and National Social Science Foundation, China under grant number [14BJY198].

\section{References}

[1] Ximing Yue, Jing Xu, "Effect of the Personal Income Tax in China on Residents' Income Redistribution", Economic Perspectives, Vol 6, 2013, pp. 16-25.

[2] Zhiwei Tian, Yijian Hu, Yinghua Gong, "Tax Exemption and the Redistribution Effect of Personal Income Tax", Economic Research Journal, Vol10, 2017, pp. 113-127.

[3] Guiquan Cao, Xiaofeng Qiu, "On the Reform of Exemption System of Personal Income Tax in China", Tianjin University Journal, Vol 3, 2016, pp. 217-223.
[4] Zhian Yang, Jin Guo, "Personal Income Tax Reform from perspective of Distribution Equality", Taxation Research, Vol12, 2011, pp. 23-27.

[5] Jing Xu, Ximing Yue, "How does Tax System Inequality Affect Income Distribution?", Economic Perspectives, Vol 6, 2014, pp. 60-68.

[6] Hua Li, Lingxuan Zhu, "The Equality Effect of Wage Income Tax and its Reform: An Empirical Test Based on Kakwani Index”, Contemporary Finance and Economics, Vol 2, 2016, pp. 33-42.

[7] Jiandong Chen, Yunfang Xu, Yinyin Wu, Tao Yao, "Design of Tax Rate and Tax Rate Bracket for Personal Income Tax: Based on Income Distribution Function", Taxation Research, Vol 3, 2014, pp. 34-40.

[8] Musgrave R. A., Thin Tun, "Income Tax Progression, 1929-48", The Journal of Political Economy, Vol 56 (6), 1948, pp. 498-514.

[9] Lan Zhang, Ganna Zhou, "The Progressivity of the Personal Income Tax and the Calculation of Redistribution effect", Tax Research, Vol1, 2018, pp. 53-58.

[10] Kakwani Nanak C, "On the Measurement of Tax Progressivity and Redistributive Effect of Taxes with Applications to Horizontal and Vertical Equity", Advances in Econometrics, Vol 3, 1984, pp. 149-168.

[11] Kakwani Nanak C, "Measurement of Tax Progressivity: An International Comparison ”, Economic Journal, Vol 345, 1977, pp. 71-80.

[12] Verbist G., Figari F. "The redistributive effect and progressivity of taxes revisited: An International Comparison across the European Union”, AIAS, GINI Discussion Paper, 2013, pp. 88.

[13] Kim K., P. J. Lambert, "Redistributive Effect of U.S. Taxes and Public Transfers, 1994- 2004", Public Finance Review, Vol 37, 2009, pp. 3-26.

[14] James Alm, Fitzroy Lee, Sally Wallace, "How fair? Change in federal income taxation and the distribution of income, 1978-1998", Journal of Policy Analysis and Management, Vol 24 (1), 1995, pp. 5-22.

[15] Xiaolu Wang. "Off-the-books income extends income gap among residents", China Reform, Vol 7, 2017, pp. 9-13.

[16] Canming Yang, Qunli Sun, "The Size, Cause and Effects of the Hidden Economy:An Empirical Investigation of Provinces of China", Economic Research, Vol 4, 2010, pp. 93-106.

[17] Xinyi Zhou, Feng Gong, "Income Redistribution Effect of China's Individual Income Taxation from an open Perspective: Measurement, Simulation and Tax System Design", Asia-pacific Economic Review, Vol2, 2018, pp. 114-123. 